\title{
A influência do perfil de jogador do aluno no desempenho de ferramentas gamificadas no processo ensino-aprendizagem
}

\author{
Márcio Cristiano Vasconcelos de Campos $^{1}$, Tiago Bonini Borchartt ${ }^{1}$ \\ ${ }^{1}$ Departamento de Informática - Universidade Federal do Maranhão \\ Av. dos Portugueses, 1966 - Vila Bacanga, São Luís - MA, 65080-805 \\ marciocvc@gmail.com, tiago.bonini@ufma.br
}

\begin{abstract}
Gamification is often used as a tool for the teacher to transmit all the necessary pedagogical content in a motivating, engaging and creative way. This work aims to analyze the influence of the student's player profile on the performance of gamified tools in the teaching-learning process.
\end{abstract}

Palavras-chave: Gamification. Player profile. Teaching-learning process.

Resumo. A gamificação é utilizada com frequência como ferramenta para o docente transmitir todo o conteúdo pedagógico necessário de forma motivadora, engajante e criativa.. Este trabalho tem como objetivo a análise da influência do perfil de jogador do aluno no desempenho de ferramentas gamificadas no processo ensino-aprendizagem.

Palavras-chave: Gamificação. Perfil de jogador. Processo ensino-aprendizagem.

\section{Introdução}

Uma definição de gamificação que mais se ajusta a área de aprendizagem seria a utilização de mecânica, estética e pensamento baseados em jogos para o engajamento de pessoas, motivando a ação, promovendo a aprendizagem e buscando resolução de problemas [Alves, 2015]. Fazer uso da gamificação significa fazer com que os alunos aceitem desafios abstratos, definidos por regras, onde há interação e tendo feedback com obtenção de resultados e reações emocionais, tudo isso utilizando elementos de jogos (competição, cooperação, exploração, premiação e storytelling) [Alves, 2015].

De acordo com [Alves e Coutinho, 2016] a gamificação analisa quais os elementos que estão no design dos jogos e o fazem divertido e adapta-os para contextos que não são jogos, criando uma camada de jogo a esse contexto. Gamificar não é simplesmente transformar qualquer atividade em um jogo, e sim aprender a partir dele encontrando elementos que melhorem uma experiência sem deixar o mundo real, tornando essa experiência mais divertida e engajadora [Alves, 2015].

Este artigo tem como objetivo fazer uma análise da influência do perfil de jogador do aluno no seu desempenho no processo ensino-apredizagem em ferramentas gamificadas e para tal foi implementada uma ferramenta chamada GamiBR(gamibr.com) que propõe diversas mecânicas específicas que atendem a cada tipo de perfil de jogador, no caso, os perfis de jogador propostos por Bartle. 


\section{Classificação do Perfil do Jogador}

Os alunos têm diferentes reações emocionais e expectativas à mecânica do jogo, isso se deve a tipologia dos jogadores que servirá de base para uma gamificação adequada. Segundo Kapp (2012), existem vários modos diferentes de ver tipos de jogadores e como eles interagem com o ambiente de jogo e com outros jogadores. Uma das classificações mais relevantes na literatura foi proposta por Richard Bartle, onde são definidos quatro tipos de jogadores conforme suas características, preferências de interação e comportamento que devem ser consideradas tanto no design de games quanto em soluções gamificadas [Alves, 2015]:

- Predadores (Killers) - seu principal objetivo no jogo é ganhar e derrotar os adversários, e estão dispostos a tudo para alcançar seu objetivo. Interage com outros jogadores, mas de forma intensa e competitiva.

- Conquistadores (achievers) - jogadores que estão em busca de realizações dentro do contexto do jogo, querendo sempre estarem na liderança e valorizam esse status. São gentis com outros jogadores e estão mesmo interessados em recompensas, pontos ou passagem para outro nível superior.

- Exploradores (explorers) - sempre buscam razões e motivos, tentando descobrir o máximo possível sobre o que o jogo propõe. Gostam de investigar e desenvolver habilidades que possam ajudar no objetivo.

- Comunicadores (socializers) - seu maior interesse é se relacionar com o outros jogadores e também organizá-los. Usa o jogo como meio para socializar com as pessoas.

Para a obtenção do perfil de jogador geralmente é necessário usar questionários de acordo com a tipologia usada, como o objetivo de identificar qual o tipo de jogador predominante do aluno, além de mostrar o quanto de outros perfis de jogadores ele possui [Oliveira Júnior; Barbosa, 2016]

\section{Combinação das Mecânicas de Jogo com os Perfis de Jogador}

\subsection{Mecânicas}

Os recursos dentro de um jogo podem ser definidos como um conjunto indissociável de elementos de design, que materializam um conjunto de dinâmicas de jogo, como, por exemplo, tabelas de classificação e troféus. Uma ferramenta gamificada deve se propor a selecionar as mecânicas mais adequadas ao tipo de jogador no ambiente de aprendizagem[Lavoué, et al., 2018].

Após a aplicação das mecânicas usa-se um segundo questionário visando obter os dados necessários para avaliar o engajamento e motivação dos alunos, além de verificar se a ferramenta obteve resultados positivos no processo ensino-aprendizagem. Segundo [Andrade, 2018], de acordo com a tipologia de jogadores há mecânicas adequadas a cada tipo de perfil no ambiente de uma ferramenta gamificada:

- Conquistadores: como esse jogadores tem como principal objetivo o acúmulo de recompensas e restringem suas interações sociais apenas para obtenção de informações que o levem a mais desafios. É necessário que o ambiente lhe proporcione recompensas constantes como pontos, medalhas, troféus e desafios. Rankings podem ser usados como feedback do seu desempenho. 
- Exploradores: procuram sempre novas experiências e informações sobre o sistema entendendo como ele funciona e buscando maneiras alternativas para cumprir as tarefas. O conhecimento do jogo é a sua recompensa. Elementos básicos como pontos e medalhas não o motivam, então pode-se abordar com as atividades sendo divididas em níveis ocultos, estimulando sua curiosidade, ou utilizar pontos como forma de progressão.

- Socializadores: são mais interessados em sociabilizar no jogo, gostam de conversar e criar vínculos de amizade com outros jogadores, ou somente observar o comportamento dos outros. Atividades colaborativas e canais de comunicação podem ser boas opções para aumentar a motivação.

- Assassinos: associados a jogadores mal comportados, podem ter bons níveis de interação com os outros. Pode-se utilizar recompensas por pontuações que os coloquem em vantagem sobre os demais. Uma opção no ambiente educacional seria permitir que os mesmos pudessem desafiar outros jogadores a executar determinada tarefa onde o vencedor ganhe pontos e o perdedor perca.

\subsection{Mecânicas propostas na ferramenta GamiBR}

Seguindo o trabalho de [Andrade, 2018], mecânicas foram propostas para cada um dos perfis de jogadores da tipologia de Bartle em uma ferramenta gamificada em ambiente educacional, a GamiBR. Essas mecânicas abordaram as mecânicas de pontuação, de níveis, de medalhas, de sociabilização e quadro de líderes.

Com isso, a ferramenta além de não limitar a gamificação ao PBL (points, badges, and leaderboards), procura despertar a motivação intrínseca oferecendo os recursos que lhe são mais interessantes, inclusive podem ser utilizados como meio para agrupar os alunos em atividades como a gerência de projetos e divisão de tarefas.

\subsection{Validação da Ferramenta GamiBR}

A ferramenta GamiBR foi aplicada no $1^{\circ}$ semestre do ano letivo de 2020 do Instituto Federal do Maranhão. No IFMA foi aplicada nos componentes curriculares de Sistemas Operacionais, Redes de Computadores I e Redes de Computadores II do curso de Sistemas de Informação das quais sou o professor.

No presente trabalho, na primeira semana todas as mecânicas ficaram disponíveis para todos os perfis, para avaliar o comportamento dos alunos. Na segunda semana, $50 \%$ (cinquenta por cento) da turma utilizou as mecânicas mais adequadas ao seu perfil predominante, enquanto os outros $50 \%$ (cinquenta por cento) utilizaram as mecânicas adequadas para o seu perfil menos predominante, para aferirmos a influência através desse teste cego.

Os resultados foram tabulados com a quantidade de alunos por perfil de jogador com suas tarefas e desafios realizados e postagens feitas na ferramenta. Com isso, observouse as diferenças de atividades dos alunos com relação às mecânicas disponíveis ou não para seu perfil de jogador. 


\section{Conclusões e trabalhos futuros}

Após o período de uso da ferramenta, foi aplicado um questionário avaliativo da ferramenta com 10 questões para analisar a ferramenta em si, com seus aspectos visuais e interesses que a mesma despertou ao ser usada pelo aluno, além de verificar se houve influência do perfil de jogador no aprendizado.

Foi possível verificar que, ao se considerar o perfil de jogador do aluno em ferramentas gamificadas, houve efeitos positivos em torno de $60 \%$ ao oferecer mecânicas mais agradáveis a cada tipo de perfil de jogador, aumentando assim o comprometimento e engajamento no processo ensino-aprendizagem.

Os resultados também mostraram que houve por parte dos alunos uma melhoria na motivação ao usar a ferramenta, resolvendo suas tarefas e desafios e vendo seu progresso pelo mapa disponibilizado. Também foi possível verificar, através do questionário que a ferramenta não surtiu o efeito desejado em alguns caso, onde os alunos eram indiferentes as mecânicas apresentadas ou não se sentiram motivados em utilizá-la.

Os resultados também mostraram que é necessário continuar investigando quais benefícios que os vários perfis de jogadores trazem para a gamificação, criando e/ou adaptando as mecânicas de jogos a eles. Em geral, os resultados foram animadores e nos encorajam a continuar nessa linha de pesquisa. Em futuros trabalhos a partir dessa dissertação, pode-se destacar:

- Oferecer na ferramenta, além dos perfis de jogadores de Bartle, outras tipologias de jogadores para verificação de sua eficácia;

- Levantar novas maneiras de gamificação e aplicá-las na ferramenta GamiBR;

- Pesquisar sobre perfis de aprendizagem e combiná-los com tipologias de jogadores, possibilitando assim uma maior personalização para a motivação e engajamento.

\section{Referências}

Alves, Flora. (2015) Gamification: Como Criar Experiências de Aprendizagem Engajadoras: Um Guia Completo, do Conceito à Prática, $2^{\mathrm{a}}$ Edição, DVS Editora.

Alves, L. e Coutinho, I. J. (2016) Jogos Digitais e Aprendizagem: Fundamentos para uma Prática Baseada em Evidências, Campinas, Papirus Editora.

Andrade, H.F.R. Gamificação personalizada baseada no perfil do jogador. Tese (Doutorado em Ciência da Computação e Matemática Computacional). São Carlos, p. 198. 2018.

KAPP, Karl M (2012) The Gamification of Learning and Instruction: Game-based Methods and Strategies for Training and Education, Pfeiffer.

Lavoué, É., Monterrat B., Desmarais, M. e George, S. (2018) Adaptive Gamification for Learning Environments, IEEE Transactions on Learning Technologies, p. 1-13, Manuscript.

Oliveira Júnior, J. A. e Barbosa, A. A. (2016) Perfis de Jogadores em Contextos de Ensino/Aprendizagem em Disciplinas de Programação, In: V Congresso Brasileiro de Informática na Educação [CBIE 2016], Anais dos Workshops do V Congresso Brasileiro de Informática na Educação [CBIE 2016], p.1137-1146. 